\title{
«La comunidad es base, trinchera de la guerra popular». Izquierda, campesinismo y lucha armada: Huancavelica, 1974-1982
}

"La communauté est la base, la tranchée de la guerre populaire». Gauche, paysannat et lutte armée: Huancavelica, 1974-1982

"The Community is the Foundation, the Trench of the Popular War". The Left, the Peasants and the Armed Struggle: Huancavelica, 1974-1982

\section{Ricardo Caro Cárdenas}

\section{OpenEdition}

Journals

Edición electrónica

URL: http://journals.openedition.org/bifea/5233

DOI: $10.4000 /$ bifea.5233

ISSN: 2076-5827

Editor

Institut Français d'Études Andines

Edición impresa

Fecha de publicación: 1 agosto 2014

Paginación: 265-283

ISSN: 0303-7495

Referencia electrónica

Ricardo Caro Cárdenas, « «La comunidad es base, trinchera de la guerra popular». Izquierda, campesinismo y lucha armada: Huancavelica, 1974-1982 », Bulletin de l'Institut français d'études andines [En línea], 43 (2) | 2014, Publicado el 08 agosto 2014, consultado el 10 diciembre 2020. URL : http://journals.openedition.org/bifea/5233 ; DOI : https://doi.org/10.4000/bifea.5233

\section{(c)}

Les contenus du Bulletin de l'Institut français d'études andines sont mis à disposition selon les termes de la licence Creative Commons Attribution - Pas d'Utilisation Commerciale - Pas de Modification 4.0 International. 


\title{
«La comunidad es base, trinchera de la guerra popular». Izquierda, campesinismo y lucha armada: Huancavelica, 1974-1982*
}

\author{
Ricardo Caro Cárdenas**
}

\begin{abstract}
Resumen
Este artículo aborda la historia de las relaciones entre la izquierda marxista peruana y su ala campesinista radical durante los años de la dictadura militar (1968-1980). En ese marco se enfoca en las redes sociales y en los vínculos políticos que definieron las opciones por el compromiso o por la ruptura y la guerra. En particular se sigue la carrera política de Justo Gutiérrez Poma, un destacado dirigente de la Federación Departamental de Comuneros y Campesinos de Huancavelica (FEDECCH) y del Frente de Defensa del Pueblo (FDP). La búsqueda de una vía revolucionaria por parte de este dirigente reúne y condensa las diversas opciones que expresó el radicalismo izquierdista de la época.
\end{abstract}

Palabras clave: Huancavelica, campesinismo, izquierda peruana, lucha armada

«La communauté est la base, la tranchée de la guerre populaire». Gauche, paysannat et lutte armée : Huancavelica, 1974-1982

\section{Résumé}

Cet article traite de l'histoire des relations entre la gauche marxiste péruvienne et son aile paysanne radicale pendant les années de la dictature militaire (1968-1980). Dans ce contexte, nous abordons les réseaux sociaux et les liens politiques qui ont défini les options pour le compromis ou pour la rupture

* Este artículo es un extracto de mi tesis de maestría en historia, en preparación. Agradezco los comentarios de Cecilia Mendez a una primera versión, también a Jesús Cosamalón y Valérie Robin por sus comentarios a esta última.

** Sociólogo. Dirección Académica de Responsabilidad Social de la Pontificia Universidad Católica del Perú. E-mail: rcaroc@yahoo.com 
et la guerre. Nous suivons en détail la carrière politique de Justo Gutierrez Poma, un éminent dirigeant de la Fédération départementale des comuneros et paysans de Huancavelica (FEDECCH) et le Front de Défense du Peuple (FDP). La recherche d'une voie révolutionnaire de ce leader réunit et condense les différentes options exprimées par le radicalisme de gauche de cette époque.

Mots-clés : Huancavelica, mouvement paysan, péruvien gauche, la lutte armée

\title{
"The Community is the Foundation, the Trench of the Popular War". The Left, the Peasants and the Armed Struggle: Huancavelica, 1974- 1982
}

\begin{abstract}
This article discusses the history of relations between the Peruvian Marxist left wing and their radical peasant faction during the years of the military dictatorship (1968-1980). In this context we focus on the social networks and the political ties that defined the options for compromise or for rupture and war. In particular, we follow the political career of Justo Gutierrez Poma, an outstanding leader of the Federación Departamental de Comuneros y Campesinos de Huancavelica (FEDECCH) and the Frente de Defensa del Pueblo (FDP). The search for a revolutionary path on the part of this leader brings together and condenses the various options that the leftist radicalism expressed at the time.
\end{abstract}

keywords: Huancavelica, peasant movement, Peruvian left, armed struggle

No es difícil observar que nuestro conocimiento sobre el PCP-Sendero Luminoso aún está marcado por sus orígenes ayacuchanos y la historia de la jefatura de Abimael Guzmán en ese grupo. Como contrapartida, salvo el caso ayacuchano, es poco lo que sabemos todavía sobre los orígenes de la lucha armada en la sociedad regional y en su escenario político en particular. Buscando una perspectiva distinta, en este ensayo nos aproximaremos a la trayectoria de un mando político-militar del PCPSendero Luminoso en el comité zonal de Huancavelica, seguiremos su trayectoria política en los años previos al inicio de la insurrección subversiva, acercándonos a las relaciones que contextualizaron las opciones que finalmente lo decidieron por el proyecto armado. De este modo espero contribuir a reconocer el perfil social de los activistas de la lucha armada al comenzar la guerra, establecer sus vínculos y posicionarlos en la historiografía regional reciente, para conseguir así al rescate de un tipo de actor invisibilizado o marginal en los relatos oficiales y, no está demás decirlo, en la memoria colectiva de la organización que lideró Guzmán1.

Hace algunos años, durante un trabajo de campo en el distrito de Acobambilla, tuve las primeras noticias sobre un mando subversivo llamado «Raúl» quien a la cabeza de una columna del PCP-Sendero Luminoso había logrado dominar los distritos de la zona, dejando una estela de miedo, desplazamientos, muerte y destrucción. Lo que me sorprendió fue escuchar que mis interlocutores sabían que se llamaba Justo Gutiérrez Poma, que había sido en los años setenta un conspicuo dirigente de la federación campesina departamental y que era oriundo de Sacsamarca, una

1 Además de la bibliografía mencionada, esta investigación se apoyó en entrevistas en Lima, Huancayo y Huancavelica, así como en el trabajo de archivo en la Gobernación de Huancavelica (ex Prefectura) y en la Confederación Campesina del Perú. 
comunidad próxima a la capital de Huancavelica. Antes de entender cómo se había llegado a su exclusión en los relatos oficiales, me propuse indagar en su biografía y trayectoria política. ¿Cómo es que pasó de liderar y representar un gremio campesino a ser un militante de la organización política más letal que haya enfrentado el campesinado peruano? ¿Fue el suyo un proceso singular o su caso podría expresar un fenómeno más amplio de radicalización y extremismo campesino? Sin pretender respuestas claras y definitivas, el presente artículo reconstruye su trayectoria y sugiere un par de hipótesis explicativas sobre el personaje.

\section{LA PRESENTACIÓN DEL PERSONAJE}

Justo Rufino Gutiérrez Poma nació en 1950 en la por entonces Comunidad de Indígenas de Sacsamarca, a una hora de caminata de la ciudad de Huancavelica. Era el tercero de cinco hermanos². Su padre, Valerio Gutiérrez — que sería asesinado por el ejército en 1984-, era parte de una conocida familia de la localidad que se dedicó por muchos años al arrieraje, la ganadería y el comercio en Acobamba y Castrovirreyna. Justo acompañó a Valerio en esos viajes y creció como un muchacho más de la comunidad participando, por ejemplo, en los campeonatos provinciales de futbol con el equipo local. No es difícil imaginar que en esos años, los viajes a través de haciendas y comunidades con marcado sello étnico hayan configurado una experiencia formativa para su futura identificación con la comunidad campesina andina. Estudió la primaria en Sacsamarca y la secundaria en Huancavelica, terminándola en Lima, en la Gran Unidad Escolar Melitón Carbajal, tiempo en que vivió junto con un primo mayor que trabajaba en la Pontificia Universidad Católica del Perú. Este periodo en Lima terminó con un frustrado intento de ingresar a una universidad en 1970. No mucho después retornará a Huancavelica, donde se casará con Marcelina, una sacsamarquina con quien tendrá varios hijos antes de que ella muera en una emboscada del ejército, en 1985.

La historia de los Gutiérrez contaba con algunos miembros destacados en el movimiento campesino, por lo que no es imposible imaginar un escenario familiar atravesado de la historia de luchas y discursos de reinvindicación campesina. En los años setenta, muchas comunidades huancavelicanas —entre ellas Sacsamarca - se sumaron a la lucha rural contra la servidumbre y el trabajo impago, por educación y acceso a más tierras. Sebastián Gutiérrez, hermano de Valerio, participó en 1965 en la fundación de la Federación Departamental de Comunidades y Campesinos de Huancavelica (FEDECCH). La federación contó desde sus orígenes con la asesoría del Partido Comunista (Unidad), al que seguirá en su respaldo al velasquismo y a la reforma agraria de 1969. Uno de los hijos de Sebastián, Zenón, seguirá sus pasos como dirigente en el barrio de Yananaco y en el Frente de Defensa en la ciudad de Huancavelica, en paralelo con la carrera dirigencial de su primo Justo, con quien también ingresará a Sendero Luminoso ${ }^{3}$.

2 Los dos menores, con Justo a la cabeza, ingresarían a Sendero Luminoso.

3 Zenón Gutiérrez Escobar morirá en la matanza de El Frontón en 1986. 


\section{REDES Y POLÍTICA}

En 1970 Huancavelica había sido declarada zona de reforma agraria, pero sus efectos concretos llegaron cuatro años más tarde, cuando se creó la SAIS Huancavelica n. ${ }^{4}$ 40. El rápido rechazo que recibió en muchas comunidades, determinó que la sectorial huancavelicana del Sinamos —la agencia política del gobierno - viera por conveniente realizar acciones de difusión y capacitación que alejaran las suspicacias. Para ello realizó una convocatoria pública a fin de «propiciar la movilización social y el surgimiento de nuevos promotores y dirigentes campesinos, mediante una capacitación adecuada» ${ }^{4}$. Según recuerdan quienes lo conocieron, debe haber sido por esta época que Justo Gutiérrez Poma se incorporó a la Juventud Revolucionaria del Perú (JRP). La JRP era un brazo orgánico del Sinamos —una suerte de voluntariado juvenil— que promovía la captación y organización de los universitarios y jóvenes entusiastas dentro de los programas y actividades desplegados por las medidas reformistas. Una vez allí debe haber recibido capacitación política y adiestramientos para la promoción social, y aunque el detalle de sus tareas se desconoce, es muy probable que estas se relacionasen con el proceso de afectación y organización rural. Como fuere, el liderazgo que alcanzó entre sus pares en la JRP — donde llegó a ser subsecretario de la sección huancavelicana-, hizo patente sus capacidades y dejó algún recuerdo de su paso entre sus compañeros de generación.

¿Fue en la JRP donde comenzó a elaborar las convicciones campesinistas? Con alguna seguridad la experiencia lo perfiló políticamente, asimilando el discurso nacionalista del régimen y predisponiéndolo a aceptar una ideología y sentimientos que tuvieron en Túpac Amaru, por ejemplo, a un ícono perdurable que Gutiérrez Poma ensalzará hasta su adhesión a la lucha armada. No mucho después, tras el golpe a Velasco (agosto de 1975) y resintiendo una creciente crisis económica, el régimen militar inició un paulatino abandono del proceso de reformas. Hasta donde se sabe, Gutiérrez Poma continuó en la JRP hasta el segundo semestre de 1976, mientras en Huancavelica los cambios mellaban el liderazgo de la FEDECCH, acelerando también la crisis de la SAIS tras una clarinada de denuncias por su mala administración, abusos y corrupción.

\section{1. Desco y la nueva izquierda}

En 1976 entró a trabajar en Huancavelica la organización no gubernamental Desco. Sus funcionarios, intelectuales con militancia política en la izquierda, pronto hicieron contacto con el joven sacsamarquino cuyo liderazgo y experiencia rápidamente lo hicieron necesario. De hecho la ahora Comunidad Campesina de

4 «Acciones de difusión y capacitación para diferentes campesinos de las unidades de producción que conforman los PIAR Huando e Ichu del departamento de Huancavelica». Sinamos. Huancavelica, diciembre de 1972. Oficina de Sinamos. Carpeta 8 Oficios Recibidos Ministerio de Fomento y Obras Públicas 1972. Archivo de la Gobernación de Huancavelica en adelante AGH. 
Sacsamarca fue elegida para ser el centro de experimentación de varios proyectos de desarrollo que incluían, por ejemplo, piscigranjas, tambos comunales, entre otros. La comunidad contaba con una organización estable y una población bastante articulada al mercado y la capital huancavelicana, mostrando así garantías para un emprendimiento participativo y sostenible. Con Gutiérrez Poma hubo además un interés de ida y vuelta. En efecto, cierta amistad y cercanía política capitalizaron un vínculo que solo romperá la guerra años después.

Los de Desco llegaban con una importante experiencia de respaldo a la Confederación Campesina del Perú (CCP). Su cercanía a la dirigencia del gremio nacional les permitirá hacer el puente entre esta y los jóvenes dirigentes campesinos huancavelicanos reunidos en la alicaída FEDECCH. Para Gutiérrez la red de intercambios en las que se insertó le permitió acceder a lecturas e información política y acompañar las tareas de capacitación y asesoría que ofrecían los promotores izquierdistas. Algunos de estos recuerdan a Gutiérrez como un joven ávido por las novedades políticas, de carácter tranquilo y proclive al perfil bajo, a pesar de una natural presencia escénica. Un entrevistado recuerda que el trato de «compañero/a» que daba Gutiérrez en sus intercambios contrastaba con el «tuteo» con el que — por ejemplo— se desenvolvía su primo Zenón. «Ser dirigente le gustaba», recuerda un pariente que entró a trabajar a Desco. Como un líder «absolutamente campesino» resume su recuerdo de Justo otro entrevistado, mientras que a Zenón lo ve más urbano y confrontacional. Estos y otros entrevistados más recuerdan su inquietud intelectual y la urgencia por hilvanar su experiencia con un sentido colectivo revolucionario.

Pronto la evolución y el faccionalismo en la variopinta izquierda limeña se reflejó en la escena huancavelicana y, por supuesto, en Desco. Así, algunos de sus profesionales pasaron a militar en Vanguardia Revolucionaria-Proletario Comunista (VR-PC), otros en el Partido Comunista Revolucionario (PCR), ambos escindidos de Vanguardia Revolucionaria. Aunque a Justo Gutiérrez Poma la cercanía a las discusiones entre militantes debe haber interesado, estas divisiones y los mutuos recelos izquierdistas lo mantendrán distante y reacio al compromiso partidario.

\section{2. Los vínculos indianistas}

Hacia 1976 o 1977, a través del primo que trabajaba en la Universidad Católica, Gutiérrez Poma se acercó a un grupo de estudiantes indianistas Ilamado TEA (Taller Experimental de Arte) quienes difundían la música y el arte andino, formando con el tiempo un colectivo activista llamado Amaru Runa. Un músico cusqueño, Ricardo Peralta, aportó a Amaru Runa con temas y motivos indigenistas que contribuyeron a darle una definición política «comunitarista» y un «cierto aparato simbólico». El principal promotor y líder del grupo le añade más matices a la naturaleza de Amaru Runa:

nosotros hablábamos de una recomposición de las confederaciones de comunidades en donde la asamblea comunal tenía el poder, no de ningún 
partido que se montara sobre las comunidades y que impusiera comités populares revolucionarios ni nada por el estilo, o sea la comunidad es soberana, la asamblea comunal es soberana, y ellos determinan qué cosa se va a hacer y la determinación de las asambleas de comunidades era avanzar a un periodo superior digamos, de reestructuración de las confederaciones zonales, lo que iba a posibilitar después una confederación a nivel del país, y no solo del país sino de Bolivia y Ecuador 5 .

Estas ideas fueron asimiladas por Gutiérrez Poma, quien las expondrá en la FEDECCH y en las comunidades que recorrerá como dirigente gremial. Por su parte, Amaru Runa llegó a plantearse tareas más amplias, algunos objetivos políticos, aunque sus esfuerzos no pasaron de ser embrionarios, consiguiendo contactar con personas y grupos en diversas partes del país. Algunas de sus ideas se diseminarán tiempo después a través del vocero de la FEDECCH: Voz Campesina Huancavelicana. El vínculo con el TEA fue significativo también por las relaciones personales y políticas que aproximaron a universitarios y sacsamarquinos, por el apoyo que los primeros darán a Gutiérrez en su cargo de secretario general de la FEDECCH ya sea a través de charlas, publicaciones o visitas temporales a la comunidad6. Como recuerda un miembro del TEA que conoció de cerca a Gutiérrez:

él comulgaba con nuestras ideas de colectivismo agrario, en la revaloración de las comunidades, de que había que fortalecer lo colectivo, y combinar lo colectivo con lo individual porque no era tampoco cien por ciento colectivo sino que había que combinar ambas cosas.

No obstante la proximidad discursiva, las ambiciones políticas de Amaru Runa no siguieron el mismo derrotero que ya por entonces había encontrado Gutiérrez en su búsqueda de una vía revolucionaria satisfactoria. Según recuerda su fundador, a fines de los setenta Gutiérrez expresaba con más vehemencia sus nuevas creencias ideológicas, cargadas de jerga marxista leninista. Un trabajador de Desco que lo frecuentó entonces, objeta que Gutiérrez tuviera alguna afinidad de ideas con TEA, «puede que al comienzo» de su etapa como dirigente, señala, porque luego de su acercamiento a la FEDECCH en 1977 «Justo pasa a ser eminentemente político, tiene una lectura política y dogmática». Es muy probable que su búsqueda lo acercara al PCR, grupo que se había hecho cargo de un discurso cargado de referencias indianistas y maoístas, armado con una retórica de lucha armada con la que se propagandizaba. La elección de Justo Gutiérrez Poma como Secretario General de la FEDECCH en agosto de 1977 y la circunstancia de un encierro en la cárcel en 1979 delatará esa proximidad sin compromisos aparentes.

5 Entrevista con el fundador del TEA, Lima, 11 de setiembre del 2012. Otro activista entrevistado recordó que para el grupo «la comunidad [campesina] era una estrategia de supervivencia de la gente, y con una tradición muy fuerte, de atrás. Entonces [la comunidad] se había adaptado 500 años y podía seguir adaptándose»

6 En 1977 los activistas de TEA publicaron, por ejemplo, los acuerdos del VII Congreso de la FEDECCH realizado el 27 y 28 de agosto de ese año. 


\section{3. Un nuevo dirigente en la FEDECCH}

Uno de los responsables del PCR huancavelicano recuerda que el ascenso de Justo Gutiérrez como dirigente en el VII Congreso de la FEDECCH tuvo que ver con la falencia de cuadros campesinos entre los grupos políticos locales. No es tan cierto, había cuadros dirigentes como el joven Carlos Taipe de Tayacaja o el veterano Rufino Castellanos de Palca, pero Justo Gutiérrez - un activista con un destacable capital social y político en los ámbitos de la SAIS — centró un consenso alrededor suyo y fue nombrado Secretario General7. Así, el desenlace no favorecía a ningún grupo en particular y encumbraba a un líder capaz aunque esquivo a las influencias partidarias. El nuevo liderazgo gremial —casi todos los dirigentes elegidos no llegaban a los 30 años - marcaba un punto de partida para reorganizar al movimiento campesino huancavelicano. Para Justo Gutiérrez Poma, el cargo suponía la disposición de recursos y apoyos para las tareas de movilización. En ese momento de recambios y nuevos rumbos, Sendero Luminoso apenas contaba con algunos profesores de Huancavelica.

¿De qué modo se iba manifestando la postura política de Justo Gutiérrez Poma? El vocero Voz Campesina Huancavelicana (VCH), donde Justo Gutiérrez Poma aparece como director, ofrece un buen ejemplo de esto. El primer número del boletín salió muy probablemente a fines de 1977. Curiosamente el respaldo para tal efecto no provino de la CCP sino del PCR, uno de los partidos de «oposición» dentro del gremio nacional y con un interés abierto por ganar la adhesión de Gutiérrez. Los contenidos de los dos únicos números ubicados de $\mathrm{VCH}$, siguiendo la tónica del PCR, enfatizaban la identidad y autonomía comunera y la denuncia al «poder local reaccionario». Portando ilustraciones de Mariátegui y Túpac Amaru, el boletín también se adornó con el simbolismo de Amaru Runa. Fue de hecho un vehículo para propalar las posiciones indianistas del colectivo universitario - varias manos de Amaru Runa habrían aportado al boletín - así como para alcanzar informes de eventos campesinos, sobre tomas de tierras, denuncias y sobre todo para ofrecer la perspectiva indianista y campesinista de sus editores. El boletín — redactado en castellano en un medio mayormente iletrado y quechua hablante- desplegará una línea opositora a la dirección de la CCP.

\section{LUCHA SOCIAL Y RADICALISMO}

La experiencia de Justo Gutiérrez en Sinamos y la capitalización de sus vínculos con los agentes de la izquierda huancavelicana contribuyeron a perfilar sus capacidades como agitador y dirigente. Se lo apreció en la organización y movilización para el célebre Paro Nacional del 19 de julio de 1977, que permitió conjugar por vez primera la protesta de todos los actores organizados de Huancavelica, aunándose al evidente descontento nacional por la crisis económica, la miseria de la vida

7 Entrevista con un ex responsable del PCR de Huancavelica, Huancayo, 13 de octubre de 2012. 
cotidiana y la ausencia de libertades. Menos de un año después se produjo un segundo Paro Nacional, el 22 de mayo, que en Huancavelica sintonizó con las protestas y movilizaciones previas de las organizaciones del campo y la ciudad. Ese día, la violencia que se desató en la capital departamental sobrepasó la capacidad policial generando la alarma en las autoridades políticas. Un entrevistado que era dirigente de los estudiantes secundarios evocó «la comuna de París» para enfatizar el recuerdo de aquella movilización y la eventual incapacidad de la izquierda para asumir la dirección de la situación. La refriega urbana costó la vida de una decena de personas y los días siguientes la policía y el ejército realizaron un allanamiento indiscriminado de domicilios en las comunidades vecinas, así como en los barrios de la ciudad8. En la cercana comunidad de Sacsamarca, amedrentarán a la población disparando a las viviendas de los dirigentes, tomando lista de todos, registrando cada vivienda. Algo similar ocurrió en las comunidades de los distritos de Yauli, Anta, Paucará, Rosario y Acobamba donde los campesinos habían bloqueado los caminos y carreteras 9 .

En todo el país la masiva protesta social y la subsecuente represión policial opacaban el proceso de la Asamblea Constituyente (1978-1979)10, de hecho las tendencias radicales en la izquierda contemplaron con expectativa la organización y movilización popular desistiendo de aceptar la inclusión política. En el comité directivo de la CCP, particularmente, las divergencias de interpretación del proceso de transición - que unos vieron como oportunidad y otros como una trampa política-, generaron disidencias y finalmente facciones (Letts, 1981). Hacia octubre de 1977, Lino Quintanilla y Julio César Mezzich, militantes de Vanguardia Revolucionaria y los más conspicuos dirigentes campesinistas en el seno de la CCP, animarán una facción maoísta opuesta a la participación en la transición política y fundarán Vanguardia Revolucionaria-Proletario Comunista (VR-PC), congregando a bases rurales de Cajamarca, Andahuaylas, Puno, Cusco, entre otros. El nuevo grupo — tildado de «dogmático»— tras la represión y derrotas sufridas por el movimiento campesino en Andahuaylas (1974), Querecotillo (1975), entre otras, enfatizaba la urgencia de organizarlo para la lucha armada del campo a la ciudad y contra el Estado.

En Huancavelica, algunos miembros de esta facción también eran trabajadores de Desco y esa circunstancia puede haber contribuido para atraer a Gutiérrez con este grupo. Los énfasis en el discurso eran muy similares, el terreno en el que se movían era el mismo. Gutiérrez, desde su cargo gremial se había dedicado de lleno a la agitación rural organizando tomas de tierras en comunidades como Tuco, Manyacc o Parco Chacapunco en las provincias de Angaraes y Acobamba,

8 Radiogramas varios enviados por el Prefecto Ausejo Aranza, Huancavelica, 23 de mayo de 1978, $\mathrm{AGH}$.

9 Comunicación a la CCP. FEDECCH, Huancavelica, 15 de junio de 1978. Archivo de la Confederación Campesina del Perú, en adelante Archivo CCP.

10 Luego del paro del 19 de julio de 1977, la dictadura militar, encabezada por Morales Bermúdez, anunció la transición a un régimen civil y a elecciones a una asamblea constituyente para el año 1978. 
desfavorecidas por la reforma agraria y con latentes conflictos por tierras. Por otro lado, la dinámica gremial de la CCP también debe haber favorecido el acercamiento, pero es bastante probable que las afinidades entre campesinistas «dogmáticos» y Gutiérrez Poma se expresaran mejor tras los violentos eventos de mayo de 1978 y tras el distanciamiento definitivo de Mezzich y Quintanilla de VR-PC.

En efecto, impactados por la participación electoral a la Asamblea Constituyente (junio de 1978), los dirigentes «urbanos» de VR-PC abandonaron la política del boicot y se alistaron en las elecciones generales de 1980. Por su parte, los campesinistas «dogmáticos» acusaron la poquedad ideológica y política de VR-PC, al no advertir que en el campo no había tal «espectáculo electoral» sino la huella indeleble de una opresión interminable. Fue en el V Congreso Nacional de la CCP, realizado en Anta, Cusco (agosto de 1978), donde ambos dirigentes jugaron sus últimas cartas públicas.

En aquel evento la oposición la lideraron el PCR y VR-PC. El primero se presentó - recuerda un asistente- «con un discurso étnico, centrado sobre la defensa de la cultura y de la lengua Quechuas y de los Aymaras» (Montoya, 1989). El campesinismo radical de este grupo se expresó en la idea de que la comunidad debía acumular «fuerzas revolucionarias para la conquista del gobierno popular revolucionario» (Montoya, 1989). A su turno, Mezzich y Quintanilla, todavía en VR-PC, señalaron que solo el camino de la lucha armada del campo a la ciudad llevaría a la liberación nacional.

Por su parte, Justo Gutiérrez, que asistió como delegado de una FEDECCH que comenzaba a mostrar tendencias divergentes, participó en la comisión que discutió el Programa y la Plataforma de Lucha, sumándose a la moción que sustentaba la necesidad de la guerra popular prolongada, del campo a la ciudad, alcanzada por Lino Quintanilla y un conocido dirigente de Cajamarca, Félix Calderón11. Fue la única comisión donde los «dogmáticos» de la CCP ganaron por mayoría, 34 votos contra 23. Pero este resultado no tuvo réplica en el Plenario del Congreso, donde fue derrotada por 372 votos contra 94 y 21 abstenciones (SUR, 1978b: 33). En esa sesión plenaria Justo Gutiérrez, ante un vasto y acalorado auditorio mostró su cercanía hacia los «dogmáticos» proclives a la lucha armada:

Qué viva la comunidad. En cuatro siglos que existe la comunidad, se defiende desde la conquista. Contra las haciendas; el gobierno los ha sometido y convertido en SAIS dejando fuera a la comunidad. Por eso deben de recuperar la tierra, que es de ellos. Nos oprimen totalmente, nuestra cultura, costumbres, etc. Las autoridades sirven para el gobierno, son su conexión. Tenemos que bajarlos. La comunidad tiene que ser autónoma,

11 Félix Calderón, un destacado líder de la comunidad de Huacataz, fue Secretario General de la federación campesina de Cajamarca. A mediados de 1979 habría iniciado su pase a Sendero Luminoso (Taylor, 2006: cap. 3). En 1982 pasó a las armas y pronto cayó arrestado. Morirá en la matanza del penal El Frontón en 1986. 
debemos de buscar alternativas; autonomía y fortalecernos, no permitir el ingreso... La comunidad es base, trinchera de la guerra popular12.

Aunque la comunidad aparece como metáfora de una antigua resistencia campesina, la demanda de Gutiérrez no se suma al «discurso étnico» de sus pares presentes. El deseo de autonomía que manifiesta tampoco era una solicitud extraña, pero la necesidad de la «guerra popular» para alcanzarla sí lo sitúa cerca de los extremistas en esa escenografía de posturas políticas. La suerte de autarquía campesinista que propone, «sin autoridades del gobierno», estrechaba las distancias con los «dogmáticos» con quienes finalmente compartirá la derrota de sus tesis y propuestas. En otro momento, menos expuesto a las rivalidades escénicas de un plenario, expresó a un reportero sus diferencias con el conjunto del evento, alejándose de cierto izquierdismo ahí presente:

Nosotros consideramos que en un congreso de Campesinos, quienes verdaderamente deben estar discutiendo, haciendo sus mítines debemos de ser nosotros los campesinos. Pero lo que ha pasado aquí no es así y son los partidos los que hacen sus mítines en grupitos, al margen de las Federaciones; pero tampoco queremos decir que ellos no deben estar aquí porque es necesario que haya una organización política de izquierda.

A continuación Gutiérrez Poma destaca la brecha política y social que hay entre las palabras y los hechos, entre el papel subalterno que se les requiere — «vivar a los partidos»-, y el protagonismo en las decisiones que «los campesinos» demandan:

Nosotros hemos venido desde muchos rincones del Perú viajando durante muchos días en las peores condiciones, haciendo trasbordo de camión tras camión dejando nuestras chacras y nuestros animales para discutir y hablar de nuestros problemas con los otros delegados que han venido. Los campesinos hemos venido a este evento verdaderamente a discutir y sacar acuerdos de solución y no a vivar a los partidos; queremos buscar caminos de solución. Solamente así vamos a dar participación a los compañeros campesinos y comuneros que ahora no están aquí. Porque los campesinos no somos sólo los que estamos acá en el Congreso, somos demasiado, hartos y nos están esperando (SUR, 1978a: 74-75).

Gutiérrez Poma relativiza la representatividad del congreso. Acusa con cierto desdén a los partidos de la izquierda que «hacen sus mítines en grupitos». En nombre de los campesinos, reprocha que «los partidos» no los escuchen ni los convoquen a ellos, «quienes verdaderamente deben estar discutiendo». No obstante, se aproximará a los dirigentes campesinistas de VR-PC quienes, poco después del congreso, romperán con ese partido para integrarse a Sendero Luminoso.

A fines de 1978, de vuelta en Huancavelica, Gutiérrez estuvo recorriendo los Grupos Campesinos de Antacancha y Castilla, Parcco Alto, Occo, Huayanay, Chopcca (Acobamba) así como a las comunidades de Tuco y Huayllay Chico 
(Angaraes) Ilamando a la invasión de los predios de la SAIS13. En diciembre fue detenido y encarcelado, acusado de «sabotear la ley de reforma agraria». Liberado en febrero con apoyo del PCR, el activismo de Gutiérrez se intensificó el resto del año, cuando el desmontaje de la SAIS Huancavelica n. ${ }^{\circ} 40$ propició nuevas tomas y luchas intercomunales por tierras. Retomó la dirección del boletín Voz Campesina Huancavelicana, donde sus posiciones abiertamente opuestas al liderazgo de la CCP aparecen al lado de otras que siguen una opción comunera radical, con exclusión de los agentes del Estado, aunque sin invocar la lucha armada:

Nuestras comunidades sufren muchos problemas internos debido a la opresión feudal y capitalista que soportamos. Algunos «campesinos acomodados» (generalmente de origen extracomunal) en compadrería con las autoridades que el gobierno impone a la comunidad (Teniente Gobernador, Juez de Paz, Agente Municipal y policías) han afectado y golpeado la cohesión y unidad de la comunidad. Algunas de nuestras comunidades están muy desorganizadas y desestructuradas. Debemos reanimar las prácticas colectivas interrumpidas, la producción comunitaria, las tiendas comunales, etc. Debemos combatir a los elementos «degenerados»y dirigir, todos los comuneros auténticos, la Reorganización, Restructuración y fortalecimiento de nuestras comunidades ${ }^{14}$.

Otros dos eventos que se iniciaron entre mayo y junio de 1979 contextualizan la última etapa en su carrera como dirigente. Uno fue la huelga del Sutep iniciada en junio. Durante casi cuatro meses la huelga movilizó a maestros y escolares, convirtiéndose en el fermento de una politización juvenil inédita en el país. Por entonces, los pocos activistas de Sendero Luminoso insertados en el magisterio huancavelicano pudieron amplificar su discurso de lucha armada, organizando como otros partidos - grupos de estudio y redes de apoyo, básicamente urbanos. A estas actividades fue invitado el secretario general de la FEDECCH y es posible que fuese en estos intercambios que se activara el contacto con dirigentes de Sendero Luminoso ${ }^{15}$.

En agosto de 1979 se realizó en la comunidad de Sacsamarca el VIII Congreso de la FEDECCH. El objetivo de la CCP $-y$ de los partidos influyentes - era agremiar formalmente a la federación huancavelicana, conseguir un recambio en la dirigencia poniendo a sus agentes partidarios en los cargos, aislando a los «revisionistas» e «infantilistas dogmáticos» como Gutiérrez Poma. Este último, con el apoyo de sus compañeros indianistas del TEA y a través del boletín de la federación huancavelicana, había promovido desde meses antes el proyecto de una nueva confederación de bases comuneras y campesinas al margen de la CCP. Su gesto disidente lo alejó del liderazgo gremial — fue nombrado secretario

13 Of. Cir. 508-78-PH. Huancavelica 12 de diciembre de 1978. Carpeta 5 Oficios Dirigidos. 1978. $\mathrm{AGH}$.

14 Editorial. Voz Campesina Huancavelicana. Órgano Comunero de la FEDECCH. Abril-Mayo de 1979.

15 Varios entrevistados recuerdan por Huancavelica a Luís Kawata, Julio César Mezzich y Osmán Morote, quien también fue visto por Lircay y Acobamba. 
de prensa- e hizo evidente para sus compañeros de Amaru Runa y del TEA, su acercamiento más que discursivo a los grupos «dogmáticos» como Sendero Luminoso.

Dos semanas después del congreso de la FEDECCH, se realizó en Huaral el Primer Consejo Nacional de la CCP, donde directivos y delegados realizaron un balance de los acuerdos del V Congreso de 1978, para luego plantear «las tareas para avanzar en la unidad revolucionaria del campesinado peruano» y para «terminar con esta dictadura militar, en lucha por nuestro PROGRAMA de Tierra, Pan, Trabajo, Liberación Nacional y un Gobierno Revolucionario del Pueblo»16. Se llamó a luchar contra el «plan reaccionario para liquidar a los sectores más avanzados del campesinado» que luchaban por la tierra y no permitir el retorno de los gamonales y «del capital privado e imperialista en alianza con el estado reaccionario». Acusando la «represión sistemática» de la policía y de «bandas armadas de los terratenientes y gamonales», el Primer Consejo denunció la muerte «de 17 dirigentes campesinos» desde octubre de 1978, situación que confirmaba «la tesis» de la CCP de que la lucha por la tierra debía prepararlos «para nuevos y más fuertes combates contra nuestros enemigos de clase», porque se demostraba así que «la lucha por el poder tiene en la lucha por la tierra su palanca principal» 17 . En este ambiente de fervores ideológicos se continuaba despreciando el proceso electoral y «la democracia burguesa» que se iban a inaugurar pocos meses después, sin embargo se apostaba a participar buscando lograr, a través del triunfo electoral, la realización de sus consignas. En este contexto aparece la última intervención registrada de Justo Gutiérrez Poma, en la que todavía palpita la demanda por el reconocimiento de la comunidad campesina como matriz de la lucha armada y — delatando su propia búsqueda—, demandando una «dirección revolucionaria contra los campesinos ricos»:

Justo Gutiérrez.- Los programas de los partidos son aportes a las luchas del Pueblo. Critico a los que plantean la lucha armada sin garantizar las bases que la hagan posible. Esa base estará constituida por [las] comunidades. Las comunidades necesitan una dirección revolucionaria contra los campesinos ricos. Tenemos que politizar a todos los campesinos para la liberación nacional. Por eso debemos defender la comunidad18.

El Consejo declaró vacante el cargo de Secretario de Defensa de la CCP que ocupaba Julio César Mezzich desde el V Congreso. No era desconocido que los campesinistas «dogmáticos» de VR-PC se habían sumado a Sendero Luminoso, de hecho se había temido su influencia, por lo que en algún momento un emisario fue a Andahuaylas a contactarlos y entablar —inútilmente- un diálogo con ambos ${ }^{19}$. Entonces se resolvió que Mezzich había hecho abandono de sus responsabilidades

${ }^{16}$ Confederación Campesina del Perú. Convocatoria al 1er. Consejo Nacional de la CCP. Huaral, Lima, 14, 15 y 16 de setiembre de 1979. CEN-CCP, agosto de 1979. Archivo CCP.

17 Informe de la Secretaría de Prensa. Exitoso Primer Consejo Nacional de la Confederación Campesina del Perú (CCP). Lima, 19 de setiembre de 1979. Archivo CCP.

18 Actas del I Consejo Nacional de la CCP, 1-2 setiembre de 1979. Archivo CCP.

19 Lino Quintanilla morirá poco después de neumonía en Talavera. 
en el Comité Directivo Nacional, «por procesar una profunda desviación infantil que no permite comprender la importancia de luchar por la organización de los pobres del campo y de la conducción de las luchas por la tierra la que [lo] llevó a alejarse no sólo del equipo de dirección del movimiento campesino sino también de su propia base»20, su lugar lo ocupó Félix Calderón, quien en un par de años caerá detenido liderando una incursión de Sendero Luminoso en Cajamarca.

Con los cambios aprobados en el Primer Concejo de la CCP y en el VIII Congreso de la FDCCH quedaba sancionada la tendencia política gremial más proclive a la adaptación con las nuevas situaciones políticas nacionales. La pérdida de liderazgo de Justo Gutiérrez Poma en la dirección de la federación huancavelicana, así como la desaparición de Mezzich de la dirección de la CCP demostraban también la ruptura con las opciones radicales que estos dirigentes personificaban. Ello no implicó la censura ni el ostracismo de las posturas anti sistema en ambos gremios, aunque sí su pérdida de prestigio en la próxima coyuntura electoral.

\section{LUCHA ARMADA EN HUANCAVELICA}

En los meses de campaña electoral de 1980, el grueso de la izquierda recién legalizada, se ocupó de organizar y deshacer alianzas electorales que la sumieron finalmente en el desconcierto. En Huancavelica los izquierdistas replicaron sin debate lo que acontecía en Lima. En ese contexto, la presencia pública de Gutiérrez Poma apenas aparece en ocasionales memoriales que firmaba como subsecretario del Frente de Defensa fundado dos años atrás. El último de estos documentos data de octubre de 1980, cuando se realiza el Primer Congreso del Frente y del que no quedan registros conocidos. Luego, su rastro se conserva entre los recuerdos de los miembros del TEA o de los promotores de Desco, con quienes mantiene un cada vez más entrecortado y áspero diálogo. ¿Ya se encontraba comprometido con la insurrección senderista?

Las primeras acciones de Sendero Luminoso en Huancavelica ocurrieron el 28 de julio de 1980, con la voladura de torres de la red eléctrica del Mantaro y de algunos postes de alumbrado en su capital. En las elecciones municipales de noviembre atacaron el centro de votación de Anchonga quemando varias ánforas y «pregonando que las elecciones eran un engaño y que el actual Gobierno no valía nada»21. Fue el único lugar donde los comicios fueron saboteados, además que destacó el voto inválido y cierto ausentismo del elector quechuahablante. Algunos asaltantes fueron capturados y varios testigos reconocieron a pobladores de Parcco-Chacapunco y Tuco acompañando a los cabecillas22, en particular a

20 Informe de la Secretaría de Prensa. Exitoso Primer Consejo Nacional de la Confederación Campesina del Perú (CCP). Lima, 19 de setiembre de 1979. Archivo CCP.

22 Informe n. ${ }^{\circ}$ 001-SPA-80. Asunto: Informe sobre el proceso electoral municipal último, 23 de noviembre de 1980. Carpeta 3 Ministerio del Interior (Subprefecturas) 1980. AGH.

22 Reservado Of. n. ${ }^{7}$ 795-80-PH. Asunto: Remite Informe Mensual del mes de noviembre de 1980. Huancavelica, 2 de diciembre de 1980. Carpeta 1 Oficios Dirigidos Ministerio del Interior-Reservado 1980. AGH. 
Telésforo B., un ex presidente de la Junta Directiva de Buenos Aires-Parcco que había sido detenido en abril de ese año por encabezar la «usurpación» de predios privados en Anccomarca23.

\section{1. Manyacc, ensayo de orquesta}

Estas localidades, junto con la comunidad de Manyacc, se encuentran en un ámbito donde se intersectan las provincias de Angaraes, Huancavelica y Acobamba24. Ubicadas en medio de una geografía difícil y alejada, con una fuerte presión demográfica y sin tierras para crecer, no solo eran ancestralmente pobres, tampoco habían recibido beneficio alguno con la reestructuración de la SAIS. Tales circunstancias invitaron a un sector de sus comuneros a contemplar la posibilidad de apropiarse de las tierras de los predios vecinos, cuyos propietarios pronto suscribieron sendos memoriales denunciando esa amenaza.

Desde un par de años atrás los propietarios habían acusado al director de la escuela de Manyacc — un conocido dirigente del SUTE - de ser el agitador de los campesinos. Entre 1979 y 1980, Pastor Anaya, otro activista rural, pasó por la zona asesorando a los dirigentes de los anexos en su lucha por la tierra. También algunos jóvenes dirigentes, con experiencia diversa en la ciudad, habían retornado a la zona con ánimo de resolver la crisis agraria local. Uno de estos jóvenes dirigentes era Telésforo B., el más extremista y cercano a los activistas políticos que transitaron en esos años por la comunidad de Manyacc y anexos.

Es muy probable que Justo Gutiérrez Poma u otros agentes de Sendero Luminoso estuviesen visitando estos lugares por la misma época, como declararán más adelante los comuneros de Manyacc y Parcco-Chacapunco. De hecho, un sector de pobladores se encontraba bien organizado y dispuesto a ir más allá de la toma de tierras y rechazar con violencia a quienes considerasen emisarios de los propietarios o agentes del orden. En marzo de 1980, por ejemplo, un grupo de guardias civiles, acompañando a un juez, fueron a detener a Telésforo B. al anexo de Anccomarca, siendo repelidos por la población. Este dirigente irá a la cárcel un breve tiempo y poco después se incorporará a Sendero Luminoso.

\section{2. Justo va a la guerra}

Más adelante, con la profusión de atentados en el país, la ambigüedad declarativa de la izquierda local frente a la lucha armada comenzó a ser interpelada por

23 Secreto. Oficio n. ${ }^{\circ}$ 873-SE. Huancavelica 02 de diciembre de 1980. Asunto: Informe de la Situación del Frente Interno. Carpeta 3 Ministerio del Interior (Subprefecturas) 1980. AGH.

24 La comunidad de Manyacc, reconocida en 1965, fue socia de la SAIS Huancavelica n. ${ }^{\circ} 40$ desde 1974. En 1972 su población era de 700 habitantes y era casi la misma una década más tarde. La comunidad tenía una extensión menor a 500 hectáreas, de las más pequeñas en aquella zona. 
las autoridades huancavelicanas. Los reflejos anticomunistas ya avivaban a un sector del gobierno nacional que sugería mano dura contra la subversión 25 . Así, pasado el primer año de guerra subversiva, los informes mensuales de la Prefectura huancavelicana repetían mes a mes que «diferentes comunidades campesinas de nuestro medio vienen siendo ganadas por elementos del PCPSendero Luminoso, trabajando en la clandestinidad, sin que la dirigencia de los mencionados comuneros, sepan de sus labores; captan elementos disociadores y marginados de ellas, y los adoctrinan y utilizan en sus actividades de grupo, como son los atentados terroristas» todo ello «con miras a realizar atentados terroristas en esta ciudad» 26 .

El 18 de abril de 1981 se produjo un ataque a la guarnición policial de Yauli. Tras un cruce de balas los senderistas fueron vencidos, aunque cayó muerto el GC Ignacio Canteño Espinoza. Como ocurrió varias veces en esos primeros meses de guerra, la inexperiencia y la falta de apoyo local permitió la captura de algunos subversivos 27 . Pronto el grupo se organizó en el penal y comenzó una carrera de huelgas y demandas. Meses después, en octubre, Vásquez y otro interno fugaron de la cárcel de Huancavelica y marcharon hacia Sacsamarca, donde fueron auxiliados por muchachos de la localidad, probablemente simpatizantes de Sendero Luminoso.

Pocos días después la policía devolvió el golpe con la captura de cinco jóvenes sacsamarquinos en la ciudad de Huancavelica. Se les encontró «planes para atacar la Jefatura Departamental de la PIP, el Policlínico de las fuerzas policiales y el Centro Educativo "Victoria de Ayacucho" $\gg 28$. Uno de los detenidos era Alejandrino Gutiérrez Poma, de 23 años, hermano menor de Justo29. Luego de su captura la policía incursionó en Sacsamarca con brutal violencia. Por supuesto que buscaron especialmente a Justo Gutiérrez Poma. Hay versiones que indican que su familia fue muy maltratada por la policía, particularmente su esposa, lo que habría precipitado su decisión de incorporarse a la lucha armada, aunque lo más probable, como se ha visto, es que Gutiérrez Poma estuviera desde tiempo atrás vinculado con Sendero Luminoso.

La detención del grupo de Sacsamarca aceleró su entrada en la clandestinidad. No lo hizo sin anunciar a la comunidad los nuevos tiempos que se iniciaban

25 En 1980 el frente Izquierda Unida — que reunía a casi todo el espectro marxista—, se definía «por la destrucción del Estado burgués y la conquista de un Gobierno surgido de la acción revolucionaria de las masas, de la clase obrera, del campesinado y del conjunto del pueblo oprimido» (Herrera Montesinos, 2002: 713).

26 Rerservado. Of. n. ${ }^{\circ}$ 081-81-PH. Asunto: Remite Informe Mensual del mes de diciembre de 1980. Huancavelica, 23 de enero de 1981. Carpeta 1 Oficios Dirigidos Ministerio del Interior 1980. AGH.

${ }^{27}$ Los detenidos fueron el ayacuchano Freddy Cruzatt, de 21 años, quien morirá en la matanza de El Frontón en 1986; Germán Vásquez de 25 años, quien fugará poco después y Nancy B., de 20 años. Reservado. Of. No. 354-81-PH. Huancavelica, 4 de mayo de 1981. Oficios Dirigidos. Ministerio del Interior. Reservados. AGH.

${ }^{28}$ Reservado. Of. n. ${ }^{\circ}$ 829-81-PH. Asunto: Remite Informe Mensual del mes de Octubre de 1981. Huancavelica, 2 de noviembre de 1981. Oficios Dirigidos. Ministerio del Interior. Reservados. AGH.

29 Alejandrino y dos de los detenidos morirán en la matanza de El Frontón en 1986. 
con la guerra declarada por el PCP-Sendero Luminoso y tras la caída de los sacsamarquinos. El llamado a la lucha armada aparentemente fue recibido con ánimo por unos, con temor y rechazo por otros, quizás los más. Gutiérrez Poma se dirigirá, encubierto, a la zona de Manyacc, donde se reunirá con Telésforo B. y probablemente con el fugado del penal, con quienes iniciará la tarea de abrir un frente guerrillero donde el comité zonal huancavelicano de Sendero Luminoso colindaba con el zonal de Ayacucho. La fuga de los reos senderistas del penal de Huamanga el 2 de marzo de 1982, permitirá reforzar la fuerza local que se estaba constituyendo en el zonal huancavelicano.

\section{3. Cruzar el río de sangre}

Exactamente un mes después de la fuga de Huamanga, Justo Gutiérrez Poma —alias «Santos»— aparecerá públicamente en Manyacc encabezando una columna de Sendero Luminoso. La incursión, como casi todas las que seguirán hasta fin de año, tuvo como propósito propagandizar el inicio de la lucha armada, convocar el apoyo de la población y organizar a los simpatizantes. Cerca al pueblo habían situado su campamento principal y pronto el rumor que denunciaba su presencia llegó a oídos de las autoridades. Entre abril y diciembre todo el ámbito de Manyacc, Parcco-Chacapunco, Occo, Tuco y Anccomarca estuvo movilizado. Varias partidas de comuneros aprovecharon el retiro de la guardia civil de las zonas amenazadas para invadir tierras30, mientras los senderistas y sus seguidores amenazaban de muerte a los propietarios restantes o empujaban a los pobladores al saqueo de los campamentos mineros. «La zona convulsionada de Manyacc», señaló un informe del subprefecto, fue visitada por al menos dos patrullas policiales, las que fueron rechazadas con galgas por grupos de pobladores, muriendo una mujer por los disparos de la policía 31 . Los primeros días de diciembre una pareja de inadvertidos técnicos sanitarios ingresó en Manyacc, siendo sorprendidos por los subversivos que asesinaron allí mismo a uno de los jóvenes para luego luego, con Justo Gutiérrez a la cabeza y ayudados por una ominosa ausencia de lluvias32, partir con el otro técnico con rumbo a Pumaranra, al norte de Paucará, donde vivía Melchor de la Cruz, un célebre abigeo sobre el que había persistentes denuncias y conminaciones de comunidades como Chopcca. No lo encontraron, pero

30 Antes de terminar 1982 se cerraron los puestos policiales de Mejorada en la provincia de Huancavelica, los de Mayocc, Churcampa y Anco en la provincia de Tayacaja, el del distrito de Julcamarca en la provincia de Angaraes y el del distrito de Pauranga en la provincia de Castrovirreyna. «Esta situación — señala el reporte prefectural correspondiente-, ha creado un clima de sicosis en las poblaciones a que se hace referencia, por el recrudecimiento de actos de terrorismo en dichas localidades, motivando la protesta y el pedido de que se restablezca de inmediato los Puestos Policiales que se han cerrado» (Of. n. ${ }^{\circ}$ 942-82-PH. Huancavelica, 9 de diciembre de 1982. Carpeta 1 Ministerio del Interior. Oficios Dirigidos. 1982. AGH).

31 Estrictamente Confidencial. Inf. n. ${ }^{\circ}$ 032-82/SAH-IN. Asunto: Sobre las últimas ocurrencias detectadas en la jurisdicción, sobre actos de Saboterrorismo; que se indica. Acobamba, 05 de noviembre de 1982. Folder 1982. AGH.

32 La sequía llegó. Hacia febrero de 1983, más del 70\% de la campaña agrícola ya estará perdida. 
saquearon su vivienda y capturaron a su hijo y mano derecha, Eusebio de la Cruz. Poco después el técnico secuestrado fue asesinado de un balazo mientras Justo Gutiérrez, según testigos, mató a puñaladas a de la Cruz. Fue su primer asesinato y marcó un antes y un después en la carrera fratricida que seguirá durante tres años más hasta desaparecer de todo registro. Poco después, las Fuerzas Armadas asumirieron el control del departamento y una etapa mucho más violenta tendrá comienzo.

Las últimas noticias de Justo Gutiérrez Poma datan de fines de 1985. Según refirió a un pariente que buscó en Lima, luego de sobrevivir a una emboscada del ejército en julio, donde murieron su esposa y casi toda su columna, inició un proceso de cuestionamientos a sus mandos, aparentemente protestando por las desastrosas pérdidas de esos años. Confrontado y detenido por sus camaradas, escapó hacia Lima, según contó, para encontrar un arreglo con el partido. Emisarios de Sendero Luminoso fueron a buscarlo, salió con ellos y desde entonces nunca más se ha vuelto a saber de él.

\section{A MODO DE CONCLUSIÓN}

Este esbozo de una biografía política de Justo Gutiérrez Poma sugiere una manera alternativa de acercarse a los inicios de la lucha armada de Sendero Luminoso, nos muestra una trayectoria distante de la imagen corriente que apela a los orígenes del PCP-Sendero Luminoso; de otro modo interpela el relato que simplifica en las decisiones de Guzmán y sus prosélitos, el origen de la violencia política. La historia de Gutiérrez Poma invita a indagar aún más en los orígenes sociales de la violencia desatada por la subversión de los ochenta.

El PCP-Sendero Luminoso no creó a Justo Gutiérrez, su militancia en ese grupo fue el resultado de una historia previa y de decisiones pensadas que lo condujeron a su eventual asimilación a ése partido. Por otro lado, las relaciones sociales y políticas que distinguen su carrera política no son extraordinarias. Como él, una generación de líderes campesinos compartió una tradición política campesina de luchas y protestas contra el «abandono» del Estado (Heilman, 2010), al mismo tiempo que requiriéndolo o, como señala Del Pino, «buscando al gobierno» (Del Pino, 2013). El camino a la lucha armada de Gutiérrez Poma — con las redes sociales, actores, circuitos de información e intercambio que surgen de su trayectoria-, ejemplifica lo que S. Kalyvas ha llamado «la cara oscura del capital social» para dar cuenta de los pormenores sociales y políticos, poco explorados en nuestro caso, de la violencia desatada en un contexto de guerra civil (Kalyvas, 2010). El campesinismo de Gutiérrez — matizado con resabios indianistas y clasistasse inscribió finalmente en la expresión más letal de la tradición radical peruana que, paradójicamente, desindianizó su causa a favor de un maoísmo fanatizado (Rénique, 2004).

Aunque hace falta explorar más en este campo de las relaciones entre discurso y experiencia, pienso que en el caso de Gutiérrez Poma la coexistencia de 
indianismo y clasismo en sus planteamientos — con su carga de sentimientos e ideología - pudo suscitarle cierta contrariedad en el contexto de recomposición social y política que le tocó vivir. La necesidad de conciliar una «conciencia revolucionaria indígena», expresada en las luchas rurales que él mismo promovía, con la afirmación de Sendero Luminoso de que el campesino quechuahablante persistía en «la ignorancia, las supersticiones y todo el peso ideológico y cultural que le impone la semifeudalidad $\gg 33$, puede haber empujado a nuestro personaje - y a otros quizás - a una suerte de disonancia congnitiva que ni la democracia o las opciones de la izquierda, ni los discursos indianistas, ni la campesinización política pudieron resolver. Su apuesta por la comunidad campesina como «trinchera de la guerra popular» no resistió los desafíos derivados de la falta de una propuesta política desde ese lugar tan real como imaginado. ¿Fue la lucha armada de Sendero Luminoso la alternativa a este desacuerdo entre ideología y experiencia?

No he intentado ofrecer una explicación final de las opciones de Justo Gutiérrez Poma. En este sentido mi interés ha sido ofrecer un relato — breve e insuficientede las relaciones, procesos e implicaciones de una biografía que me ha servido de hilo conductor para aproximarme a una época cada vez más lejana, pero también como un puente hacia nuestro presente, todavía marcado y pendiente de una deuda con su pasado.

\section{Referencias citadas}

\section{Fuentes}

AGH, Archivo de la Gobernación de Huancavelica

Archivo CCP, Archivo de la Confederación Campesina del Perú

\section{Publicaciones}

DEL PINO, P., 2013 - «En nombre del gobierno»: políticas locales, memoria y violencia en el Perú del siglo XX. In: Las formas del recuerdo, Etnografías de la violencia política en el Perú (P. Del Pino \& C. Yezer, eds.): ; Lima: Instituto de Estudios Peruanos, Instituto Francés de Estudios Andinos.

FEDERACIÓN DEPARTAMENTAL DE COMUNIDADES Y CAMPESINOS DE HUANCAVELICA (FEDECCH), 1979 - Voz Campesina Huancavelicana. Huancavelica, Órgano Comunero, abril-mayo, 8 pp.; Lima.

GUZMÁN REYNOSO, A. \& YPARRAGUIRRE REVOREDO, E., 2014 - Memorias desde Némesis, 526 pp.; Lima.

33 «Informe, programa y tareas» [mayo, 1969], citado en Guzmán e Yparraguirre, 2014. 
HERRERA MONTESINOS, G., 2002 - Izquierda Unida y el Partido Comunista, 823 pp.; Lima: Termil editores.

HEILMAN, J. P., 2010 - Before the Shining Path. Politics in Rural Ayacucho, 1895-1980, xii +254 pp.; Stanford, California, USA: Stanford University Press.

KALYVAS, S., 2010 - La lógica de la violencia en la guerra civil, 655 pp.; Madrid: AKAL.

LETTS COLMENARES, R., 1981 - La Izquierda Peruana. Organizaciones y tenencias, 198 pp.; Lima: Mosca Azul editores.

MONTOYA, R., 1989 - Lucha por la tierra, reformas agrarias y capitalismo en el Perú del siglo XX, 279 pp.; Lima: Mosca Azul Editores.

RENIQUE, J. L., 2004 - La batalla por Puno. Conflicto agrario y nación en los Andes peruanos 1986-1995; Lima: IEP.

SUR, 1978a - Boletín Informativo Agrario, n. ${ }^{\circ}$ 6, agosto 1978: 74-75; Cusco: Centro de Estudios Rurales Andinos Bartolomé de las Casas.

SUR, 1978b - Boletín Informativo Agrario, n. $^{\mathbf{7}}$ 7, octubre 1978: 31-33; Cusco: Centro de Estudios Rurales Andinos Bartolomé de las Casas.

TAYLOR, L., 2006 - Shining Path. Guerrilla War in Perú's Northern Highlands, 1980-1997, xi+232 pp.; Liverpool: Latin American Studies. New Series 6. 